\title{
Mediating Effect of Work Self-Efficacy on the Relationship Between Psychosocial Safety Climate and Workplace Safety Behaviors Among Bank Employees After Covid-19 Lockdown
}

\author{
Abimbola A. Akanni1 ${ }^{1}$ Chris 0. Ajila², Idowu 0. Omisile ${ }^{3}$, Kelechi N. Ndubueze ${ }^{4}$
}

Submitted: 28.09.2020. Accepted: 21.02.2021

\section{Abstract}

Purpose: Studies find that psychosocial safety climate is positively associated with workplace safety behaviors. However, the mechanism through which psychosocial safety climate exerts its effect needs further investigation. Therefore, this study investigated the indirect effect of work self-efficacy in the relationship between psychosocial safety climate and workplace safety behaviors.

Methodology: Participants, who were 155 bank workers ( $F=66.5 \%$; mean age= 33.9, $\mathrm{SD}=6.4$ ), responded to an online survey of workplace safety behavior scale (WSBS), psychosocial safety climate scale (PSC-12), and work self-efficacy scale (WSES).

Results: Results from correlational analyses revealed that psychosocial safety climate positively related to workplace safety behaviors. Moreover, work self-efficacy positively correlated to workplace safety behaviors. The mediation analysis using Hayes Process Macros indicated an indirect effect of work self-efficacy in the relationship between psychosocial safety climate and workplace safety behaviors. Creating a psychosocially safe climate may enhance bank workers' safety behaviors in the period after the Covid-19 pandemic.

Keywords: bank workers, Covid-19, psychosocial safety climate, workplace safety behavior, work self-efficacy. 


\section{Introduction}

Since the outbreak of the global Covid-19 pandemic, relevant agencies and governments have continued to make strategic efforts at containing the virus's spread. One of such efforts is the closure of banks to avoid physical contact. However, since banks cannot be closed forever due to ripple effects on the economy, there is a need to partially re-open them for business with stringent measures to ensure that further virus' spread is curtailed (see Nigeria Centre for Disease Control, NCDC, 2020). Thus, safety behaviors of bank workers may be relevant in order to protect them and their customers from contracting the virus. Safety behaviors were originally defined by Salkovskis (1991) as behaviors implemented - either overtly or covertly - in specific situations to prevent feared outcomes; these are preservative behaviors implemented to prevent anticipated negative consequences (Salkovskis, 1991).

In the context of work, Griffin and Neal (2000) highlight that safety at work consists of safety compliance, which revolves around the use of appropriate personal protective equipment and following standard procedures that guide daily operations, along with safety participation (citizenship) that includes activities extending beyond the employees' formal work role (Chughtai, 2015) to include participation in safety-related campaigns and the promotion of safe work ethics among co-workers (Toppazzini et al., 2017). These elements can be strengthened by a safety initiative (Curcuruto et al., 2019) that agrees with the proactive responsibility of fostering changes that can lead to better safety practices. This is similar to the safety participation construct of Griffin and Neal (2000).

Both situational and personal factors may affect safety behavior at work (Christian et al., 2009; qtd. in Toppazzini and Wiener, 2017). Situational factors such as motivation to practice safety behaviors (Curcuruto et al., 2018), transformational leadership (Conchie, 2013; Chughtai, 2015; Muchiri et al., 2019), and ethical leadership (Chughtai, 2015) can provide the inspiration needed for subordinates to observe safety regulations and make extra efforts toward a safe workplace. Person-related factors refer to specific individual characteristics that affect workplace safety behaviors. For instance, Toppazzini et al. (2017) report that conscientious personality types are more likely to observe safety rules and practices. Similarly, organizational commitment was also found to be associated with workplace safety behavior (Curcuruto et al., 2018). The present study examined the indirect effect of work self-efficacy in association between PSC and workplace safety behaviors among bank workers after a Covid-19 lockdown. 


\section{Psychosocial Safety Climate (PSC) and Workplace Safety Behavior}

Bond et al. (2010) define PSC as a "shared belief held by workers that their psychological safety and wellbeing is protected and supported by senior management," which is considered to minimize the risk of psychological and social harm that workers may experience (Dollard et al., 2010; 2012) in the course of discharging their duties. Empirical studies on the link between PSC and workplace safety behaviors abound. For instance, PSC is reported to predict employee's health and safety status (Ansah et al., 2018), but also correlate with well-being (Ishola, 2017), improved productivity (Becher et al., 2016), conducive work environment, better work engagement, and the reduction of psychological distress and emotional exhaustion (Dollard et al., 2012).

Related studies report a link between safety culture and safety performance (Otitolaiye, 2016; Nadhim et al., 2018). In the Covid-19 lockdown, PSC is expected to facilitate safety behaviors as Lyu et al. (2018) establish among construction workers. The same is reported among the staff of analytical laboratories in Nigeria (Agaja, 2012). Previous studies on PSC's links were conducted during normal operational activities in selected organizations. Employees with a high perception of safety climate tend to display a high level of safety behaviors while both safety climate and safety behaviors may result in reduced workplace accidents (Beus et al., 2010; qtd. in Toppazzini and Wiener, 2017). Hence the need to examine the role of PSC in workplace safety behaviors among bank employees after Covid-19 lockdowns. Therefore, we propose that:

Hypothesis 1: Psychosocial safety climate will be positively associated with workplace safety behavior.

\section{Workplace Self-Efficacy and Workplace Safety Behavior}

Workplace self-efficacy is a personal factor that may impact bank employees' workplace safety behaviors in the lockdown following the Covid-19 pandemic spread. Bandura's (1997) views on the application of self-efficacy to the workplace captured "an individual's conviction (or confidence) about their abilities to mobilize the motivation, cognitive resources, and courses of action needed to successfully execute a specific task within a given context" (Stajkovic and Luthans, 1998, p. 66). Self-efficacy reflects the ability to increase effort and persist in a challenging task, which eventually increases the chance of success (Chughtai, 2015).

Past studies establish an association between self-efficacy and success at work (Loeb, 2016), workplace well-being (Singh et al., 2019), improved job performance (Towler, 
2019), and organizational citizenship behavior (Alessandri et al., 2021). Individuals who have high self-efficacy can assume more challenging goals in a persistent manner to achieve success (Towler, 2019), especially during the pandemic and public health challenges caused by Covid-19. These studies hint at a strong relationship between workplace self-efficacy and workplace safety behaviors (Chen and Chen, 2014). The higher the perceived self-efficacy of employees, the more likely they maintain workplace safety behaviors (Chen and Chen, 2014). Similarly, Nykanen, Salmela-Aro, Tolvanen, and Vuori (2019) confirm that safety intervention can lead to an increase in both safety-related self-efficacy and internal locus of control, while Curcuruto, Parker, and Griffin (2018) report that safety initiative can enhance self-efficacy beliefs and a future-focused approach to safety. Therefore, we propose that workplace self-efficacy will play a role in employees' readiness to follow safety rules and guidelines prescribed by the NCDC (NCDC, 2020) to combat Covid-19. Thus, we hypothesize that:

Hypothesis 2: Work self-efficacy will be positively associated with workplace safety behavior.

\section{Mediating Role of Work Self-Efficacy}

We proposed that PSC positively influences bank employees' workplace safety behaviors through workplace self-efficacy. A work environment with a psychosocially safe climate enhances employees' health, wellbeing, and productivity (Becher et al., 2016; Ishola, 2017; Ansah et al., 2018), which is a result of employees' perception of management commitment to and prioritization of their safety concerns. Such a work environment may motivate employees to participate and show commitment to issues that border on their own and others' safety. Bandura (1997) opines that self-efficacy is a positive personal characteristic that may positively influence behavioral outcomes.

The Covid-19 pandemic has stretched demands for workplace safety beyond specific occupations to all work settings. Employees in all occupational settings are now required to adhere to specific safety standards in order to keep themselves and others safe at work. Bank workers are also expected to actively participate in safety concerns because their inability to do so may have implications for their own and customers' health. While management is expected to commit to a psychologically safe workplace (Dollard et al., 2012; Yulita et al., 2016), employees' characteristic - such as work self-efficacy - may enhance their compliance and participation. Previous studies show that self-efficacy mediates the relationship between transformational leadership and work engagement (Prochazka et al., 2017). Hence, we hypothesize that: 
Hypothesis 3: Work self-efficacy will mediate the relationship between PSC and workplace safety behavior.

Figure 1. Theoretical research model for the study

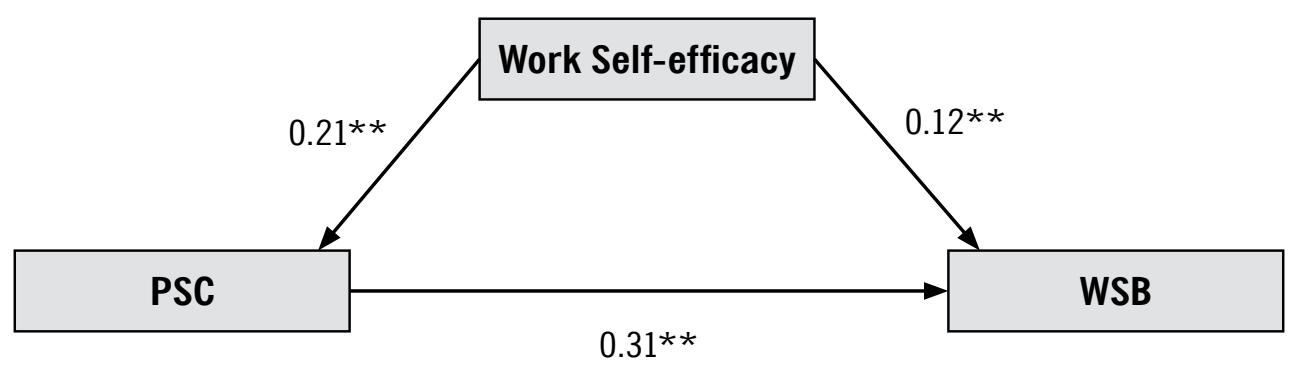

Source: own elaboration.

\section{Material and Method}

\section{Participants and Procedure}

Due to the restrictions by the current global Covid-19 pandemic, this survey was conducted online via Google forms. Participants were employees of selected banks in Nigeria. Their consent to participate in the study was sought before they proceeded to complete the questionnaire. Out of the 157 responses from bank workers who responded to the online survey, 155 results $(\mathrm{F}=66.5 \%$; mean age $=33.9, \mathrm{SD}=6.4)$ were found useable. The response rate was $98.7 \%$ and the results were gathered from May 30 to July 8,2020 . The distribution of participants by status revealed that there were 35 (22.6\%) junior staff, 72 (46.5\%) middle level staff, and 48 (31\%) of the senior cadre.

\section{Measures}

Workplace safety behaviors were assessed using the safety behavior questionnaire by Vinodkumar and Bhasi (2010). This study made use of the safety compliance and safety participation components of the scale, with eight items. Participants responded to a five-point Likert format ranging from "strongly disagree" (1) to "strongly agree" (5). The responses were summed to arrive at a global score of safety behavior at the workplace. The scale demonstrated strong internal reliability of the study $(\alpha=.91)$.

Psychosocial safety climate was measured using the 12-item psychosocial climate scale (PSC-12) developed by Hall, Dollard, and Coward (2010). The scale has four subscales 
that can either be summed or treated separately: management priority, management commitment, organizational communication, and organizational participation. This study employed a sum total to examine direct and indirect effects while the subscales were also utilized in a correlational analysis. PSC-12 had a five-point Likert response from 1 = "strongly disagree" to 5 = "strongly agree." The sum total showed a Cronbach alpha coefficient internal consistency of $\alpha=.70$

Work self-efficacy was measured with a six-item work self-efficacy subscale from the original psychological capital questionnaire developed by Luthans et al. (2007). The subscale has a five-point Likert format response format, viz. 1 = "strongly disagree" to $5=$ "strongly agree." The scale showed a strong internal consistency for this study $(\alpha=.91)$.

Table 1. Mean, standard deviation, and correlation matrix of the variables in the study

\begin{tabular}{|c|c|c|c|c|c|c|c|c|c|}
\hline Variables & Mean & SD & 1 & 2 & 3 & 4 & 5 & 6 & 7 \\
\hline 1.Age & 33.85 & 6.37 & 1 & & & & & & \\
\hline 2.Management Commitment & 10.44 & 2.35 & -0.014 & 1 & & & & & \\
\hline 3 Management Priority & 11.10 & 2.47 & -0.010 & $.752 * *$ & 1 & & & & \\
\hline 4 Organization Communication & 10.55 & 2.15 & 0.014 & $.642^{* *}$ & $.686 * *$ & 1 & & & \\
\hline 5 Organization Participation & 10.99 & 2.29 & 0.024 & $.577 * *$ & $.610 * *$ & $.620 * *$ & 1 & & \\
\hline 6 Psychosocial Safety Climate & 43.08 & 7.95 & 0.004 & $.869 * *$ & * $.894 * *$ & $.852 * *$ & $.816^{* *}$ & 1 & \\
\hline 7 Work Self-Efficacy & 23.03 & 2.98 & 0.024 & $.286^{* *}$ & *.287** & $.352 * *$ & $.357 * *$ & $.372 * *$ & 1 \\
\hline 8 Safety Behavior & 33.01 & 5.14 & -0.036 & $.367 * *$ & $.368^{* *}$ & $.423 * \star$ & $.483 * *$ & $.476 * *$ & $.515^{* *}$ \\
\hline
\end{tabular}

Source: own elaboration.

\section{Results}

The results gathered in Table 1 revealed a significantly positive association among the dimensions of psychosocial safety climate, viz. management commitment $(\mathrm{r}=.29$, $\mathrm{p}<.01)$, management priority commitment $(\mathrm{r}=.29, \mathrm{p}<.01)$, management communication commitment $(\mathrm{r}=.35, \mathrm{p}<.01)$, management participation commitment $(\mathrm{r}=.36$, $\mathrm{p}<.01$ ), and work self-efficacy. Moreover, the results revealed a positive significant 
relationship between management commitment and workplace safety behaviors $(\mathrm{r}=.37$, $\mathrm{p}<$.01), management priority and workplace safety behaviors $(\mathrm{r}=.37, \mathrm{p}<.01)$, management communication and workplace safety behaviors $(\mathrm{r}=.42, \mathrm{p}<.01)$, along with management participation and workplace safety behaviors $(\mathrm{r}=.48, \mathrm{p}<.01)$. Overall, the results showed a positive significant association between psychosocial safety climate and workplace safety behaviors $(\mathrm{r}=.48, \mathrm{p}<.01)$. Furthermore, PSC is significantly and positively associated with work self-efficacy $(\mathrm{r}=.36, \mathrm{p}<.01)$. Finally, work self-efficacy is significantly and positively associated with workplace safety behaviors $(\mathrm{r}=.52, \mathrm{p}<.01)$.

\section{Mediation Effect of Work Self-Efficacy}

The IBM SPSS process macro by Hayes (2018; v.3.4) was used to conduct the mediation analysis; the tool was recently used by researchers to estimate the mediation model (Cero and Sifers, 2013). Moreover, the capacity for the process macro to estimate model coefficient with confidence interval through bootstrapping approach was found to be beneficial (Hayes, 2013).

Table 2. Testing the mediating effect of work self-efficacy in the psychosocial safety climate: workplace safety behaviors link

\begin{tabular}{|c|c|c|c|c|c|c|c|c|c|c|c|c|c|}
\hline \multirow{4}{*}{\begin{tabular}{|l} 
Predictors \\
Variables
\end{tabular}} & \multicolumn{3}{|c|}{ Mediator Model } & \multicolumn{10}{|c|}{ Consequent Factors } \\
\hline & \multirow[b]{3}{*}{$\boldsymbol{\beta}$} & \multirow[b]{3}{*}{ SE } & \multirow[b]{3}{*}{$p$} & \multicolumn{10}{|c|}{ Dependent Variable Model } \\
\hline & & & & \multicolumn{3}{|c|}{$\begin{array}{l}\text { Total } \\
\text { effect }\end{array}$} & \multicolumn{3}{|c|}{$\begin{array}{l}\text { Direct } \\
\text { effect }\end{array}$} & \multicolumn{4}{|c|}{$\begin{array}{l}\text { Mediating effect } \\
\text { I.E (95\% Boot C.I) }\end{array}$} \\
\hline & & & & $\boldsymbol{\beta}$ & $S E$ & $P$ & $\boldsymbol{\beta}$ & SE & $P$ & $\boldsymbol{\beta}$ & SE & $L L$ & $U L$ \\
\hline Constant & 17.03 & 1.23 & 0.001 & 19.73 & 2.02 & 0.001 & 8.20 & 2.76 & .004 & - & & - & \\
\hline PSC & .14 & .03 & 0.001 & .31 & .05 & 0.001 & .21 & .05 & .001 & - & & - & - \\
\hline \multirow[t]{2}{*}{ WSE } & - & - & - & - & - & - & .68 & .12 & .001 & .15 & 08 & .004 & .306 \\
\hline & \multicolumn{3}{|c|}{$\begin{array}{c}F(1,153)=24.52 \\
p<.001 \\
R=.37, R^{2}=.14\end{array}$} & \multicolumn{3}{|c|}{$\begin{array}{c}\mathrm{F}(2,152)=42.56 \\
\mathrm{p}<.001 \\
\mathrm{R}=.60, \mathrm{R}^{2}=.36\end{array}$} & \multicolumn{3}{|c|}{$\begin{array}{c}\mathrm{F}(2,152)=44.85 \\
\mathrm{p}<.001 \\
\mathrm{R}=.47, \mathrm{R}^{2}=.23\end{array}$} & & & & \\
\hline
\end{tabular}

Note: I.E=Indirect effect, C.I= Confidence Interval, Boot= Bootstrapping, PSC=Psychosocial Safety Climate; WSE $=$ Work Self-Efficacy.

Source: own elaboration. 
The results gathered in Table 2 showed a statistically significant total effect of psychosocial safety climate on workplace safety behaviors $(\beta=0.31, \mathrm{SE}=.05, p<.001)$, but also a significantly direct effect of psychosocial safety climate $(\beta=0.21, \mathrm{SE}=.05$, $p<.001)$ and work self-efficacy $(\beta=0.68, \mathrm{SE}=.12, p<.001)$ on workplace safety behaviors. These results indicated that psychosocial safety climate and work self-efficacy independently predict workplace safety behaviors. Furthermore, the standardized indirect effect of psychosocial safety climate and workplace safety behaviors via work self-efficacy is significant $(\beta=0.15, \mathrm{SE}=.08,95 \% \mathrm{CI}=[0.004, .306])$. The overall proportion of the total effect was $60 \%$.

\section{Discussion}

The study examined the association between PSC and workplace safety behavior, along with the indirect effect of work self-efficacy in the link between PSC and workplace safety behaviors among bank workers after the Covid-19 lockdown.

As hypothesized, our findings revealed that PSC has a positive association with workplace safety behavior. Thus, management priority, commitment, communication, and participation in advancing a safe environment for daily operational activities assist employees to display safety behaviors so as to curtail the spread of the virus. Previous findings establish similar positions that PSC facilitates safety behavior (Otitolaiye, 2016; Nadhim et al., 2018; Lyu et al., 2018). This is due to the capacity of PSC to create a conducive work environment (Ishola, 2017) that enables employees to ensure adherence to safety guidelines as proposed by the Nigeria Centre for Disease Control (NCDC, 2020). Moreover, such an environment facilitates initiatives among workers (Curcuruto et al., 2018), hence when employees know that they can use their initiatives, they are likely to reciprocate by performing safety behaviors at work.

Furthermore, the study established a positive association between work self-efficacy and employee safety behaviors, which agrees with Bandura's (1986) position that a reasonable belief in one's ability to perform a task will enhance ultimate success in the pursuit of such tasks. This study suggested that bank workers after the Covid-19 lockdown show significant capacities to ensure that the spread is curtailed, thus preventing the further spread of the virus. This finding agrees with previous studies that find self-efficacy to be associated with success in tasks (Loeb, 2016; Towler, 2019) and that safety initiative is to be driven by self-efficacy (Nykanen et al., 2019). Plausibly, bank workers' beliefs in their capacities to actively follow safety measures can lead to better workplace safety behaviors and, consequently, the combating of the spread 
of the virus in their contact with customers and the customer-to-customer transmission of the virus (Covid-19).

Finally, in confirmation of the study prediction, we found that work self-efficacy mediates the relationship between PSC and workplace safety behaviors. Bandura's (1997) proposition that self-efficacy can improve chances of success was established through its role in the interplay between PSC and workplace safety behavior. Prochazka et al. (2017) establish that employees' engagement can improve with good management through self-efficacy. Thus, the possible safety behaviors that bank workers now display in the partial reopening of the economy during the Covid-19 pandemic in a psychosocially safe climate are enhanced by work self-efficacy.

The implications of the findings from this study are that practitioners and researchers may need to investigate workplace safety beyond the supposed high-risk occupations, especially after the experience of the Covid-19 lockdown. At the managerial level, this study confirmed the importance and necessity for positive PSC because when employees feel that their employers show commitment and give priority to safety concerns at the workplace, the employees reciprocate by complying with safety rules and participating in the safety behaviors, thus reducing the spread of the pandemic. Similarly, management may need to take certain practical measures to ensure that safety equipment - both for personal and customer use - is available in sufficient quantity and quality. Moreover, an appropriate monitoring procedure is essential to guarantee enforcement so employee initiatives should also be encouraged so as to enhance their self-efficacy because when employees believe that their efforts are recognized and permitted, it boosts their self-efficacy.

One of the few limitations of this study is the online nature of the survey, meaning that we were unable to precisely establish the number of people who received the link we shared against those who eventually responded to the survey. Hence, we encountered difficulties in ascertaining the response rate. We had to employ this method due to the necessity of a social distancing protocol, which forbids close contact with people during the Covid-19 pandemic. Another limitation was the cross-sectional nature of the data, which requires others to treat the results with caution. A longitudinal design would have been more appropriate but was difficult for implementation during the pandemic. Furthermore, data for this study came from employees in the banking sector in Nigeria. Thus, we call for caution when transposing our findings onto other sectors that may not meet the conditions under which this study was conducted. Therefore, we suggest that similar studies should be conducted in other sectors such as educational institutions, the health sector, and retail. 
We conclude that PSC plays a significant role in employees' workplace safety behaviors. This is because the study confirmed our hypothesis that PSC is positively associated with workplace safety behaviors. The current study was able to contribute to the expansive body of knowledge not only by establishing the positive relationship between PSC and work self-efficacy but also by enabling - through work self-efficacy - the association between PSC and workplace safety behavior. Hence, this initial study establishes an indirect effect of work self-efficacy in the association between PSC and workplace safety behavior, particularly after the Covid-19 lockdown in Nigeria.

\section{Acknowledgment}

The efforts of individuals who assisted to forward the survey link to the participants are appreciated.

\section{References}

Agaja, S.A. (2012). Appraisal of safety climate in government and private analytical laboratories in Warri Delta state, Nigeria. International Journal of Scientific \& Technology Research, 1(7), 34-35.

Alessandri, G., Filosa, L., Eisenberg, N. and Caprara, G.V. (2021). Within-individual relations of emotional, social, and work self-efficacy beliefs to organizational citizenship behaviors. Journal of Research in Personality, 91, 104073. https://doi.org/10.1016/j.jrp.2021.104073.

Bandura, A. (1997). Self-efficacy: The exercise of control. New York, NY: Freeman.

Becher, H. and Dollard, M. (2016). Psychosocial safety climate (PSC) and better productivity in Australian workplaces. A publication of Asia Pacific Centre for Work Health and Safety.

Beus, J.M., Payne, S.C., Bergman, M.E., Arthur Jr, W. (2010). Safety climate and injuries: an examination of theoretical and empirical relationships. Journal of Applied Psychology, 95(4), 713-727.

Bond, S., Tuckey, M., and Dollard, M. (2010). Psychosocial safety climate, workplace bullying, and symptoms of posttraumatic stress. Organization Development Journal, 28, 37-56.

Chen, C.F., and Chen, S.C. (2014). Measuring the effects of safety management system practices, morality leadership and self-efficacy on pilots' safety behaviors: Safety motivation as a mediator. Safety Science, 62, 376-385. https://doi.org/10.1016/j.ssci.2013.09.013.

Chughtai, A.A. (2015). Creating safer workplaces: the role of ethical leadership. Safety Science, 73, 92-98.

Conchie, S.M. (2013). Transformational leadership, intrinsic motivation, and trust: A moderated-mediated model of workplace safety. Journal of Occupational Health Psychology, 18(2), 198-210.

Curcuruto, M., Parker, S.K. and Griffin, M.A. (2019). Proactivity towards workplace safety improvement: an investigation of its motivational drivers and organizational outcomes. European Journal of Work and Organizational Psychology, 1-18. https://doi.org/10.1080/1359432x.2019.1572115.

Dollard, M.F. and Bakker, A.B. (2010). Psychosocial safety climate as a precursor to conducive work environments, psychological health problems, and employee engagement. Journal of Occupational and Organizational Psychology, 83(3), 579-599. 
Dollard, M., Tuckey, M.R. and Dormann, C. (2012). Psychosocial safety climate moderates the job demand-resource interaction in predicting workgroup distress. Accident Analysis and Prevention, 45, 694-704. https://doi.org/10.1016/j.aap. 2011.09.042.

Griffin, M.A. and Neal, A. (2000). Perceptions of safety at work: a framework for linking safety climate to safety performance, knowledge and motivation. Journal of Occupational Health Psychology, 5(3), 337-345. https://10.1037//1076-8998.5.3.347.

Hayes, A.F. (2013) Introduction to Mediation, Moderation, and Conditional Process Analysis: A Regression-Based Approach, The Guilford Press, New York, NY.

Hayes, A.F. (2018). Introduction to Mediation, Moderation, and Conditional Process analysis: A Regression-Based Approach, Second Edition. Available at: http://afhayes.com/introduction-to-mediation-moderation-and-conditional-process-analysis.html (10.04.21).

Ishola A.A. (2017). Workplace Safety Management as Correlates of Well-being among factory workers in Ibadan, Nigeria. African Journal of Social Work, 7(2).

Loeb, C. (2016). Self-efficacy at work: social, emotional, and cognitive dimensions. Mälardalen University Press Dissertations, No. 208. Sweden, Mälardalen University. Available at: https://www.diva-portal.org/smash/get/diva2:963036/FULLTEXT03.pdf (10.04.21).

Luthans, F., Youssef, C.M., and Avolio, B.J. (2007). Psychological Capital. New York: Oxford University Press.

Lyu, S., Hon, C.K.H., Chan, A.P.C., Wong, F.K.W. and Javed, A.A. (2018). Relationship among safety climate, safety behavior, and safety outcomes for ethnic minority construction workers. International Journal of Environmental Research and Public Health, 15, 484.

Muchiri, M.K., McMurray, A.J., Nkhoma, M. and Pham, H.C. (2019). How transformational and empowering leader behaviors enhance workplace safety: a review and research agenda. The Journal of Developing Areas, 53(1), 257-265.

Nadhim, E.A., Hon, C., Xia, B., Stewart, I. and Fang, D. (2018). Investigating the relationships between safety climate and safety performance indicators in retrofitting works. Construction Economics and Building, 18(2), 110-129. http://dx.doi.org/10.5130/AJCEB.v18i2.5994.

Nigeria Centre for Disease Control (NCDC, 2020). Guidelines for employers and businesses in Nigeria. Available at:

https://covid19.ncdc.gov.ng/media/files/Covid19GuideforBusinesses_1.pdf (10.04.21).

Nykanen, M., Salmela-Aro, K., Tolvanen, A., and Vuori, J. (2019). Safety self-efficacy and internal locus of control as mediators of safety motivation - Randomized controlled trial (RCT) study. Safety Science, 117, 330-338. https://doi.org/10.1016/j.ssci.2019.04.037.

Otitolaiye, V.O. (2016). The mediating effect of safety management system on the relationship between safety culture and safety performance in Lagos food and beverage manufacturing industries. Unpublished master's thesis, University Utara Malaysia.

Prochazka, J., Gilova, H. and Vaculik, M. (2017). The relationship between transformational leadership and engagement: self-efficacy as a mediator. Journal of Leadership Studies, 11(2), 22-33. https://doi.org/10.1002/jls.21518.

Salkovskis, P.M. (1991). The importance of behavior in the maintenance of anxiety and panic: A cognitive account. Behavioral and Cognitive Psychotherapy, 19(1), 6-19. https://doi.org/10.1017/S0141347300011472.

Singh, S.K., Pradhan, R.K., Panigrahy, N.P. and Jena, L.K. (2019). Self-efficacy and workplace well-being: moderating role of sustainability practices. Benchmarking: An International Journal, 26(6):1692-1708. https://doi.org/10.1108/BIJ-07-2018-0219.

Stajkovic, A.D. and Luthans, F. (1998). Self-efficacy and work-related performance: A meta-analysis. Psychological Bulletin, 124(2), 240-261. 
Toppazzini, M.A. and Wiener, K.K.K. (2017). Making workplaces safer: the influence of organizational climate and individual differences on safety behavior. Heliyon, 3(e00334), 1-16. http://dx.doi.org/10.1016/j.heliyon.2017.e00334.

Towler, A. (2019). Self-efficacy and job performance: a primer for management practitioners. Available at: https://www.ckju.net/en/dossier/self-efficacy-and-job-performance-primer-management-practitioners (10.04.21).

Vinodkumar, M.N. and Bhasi, M. (2010). Safety management practices and safety behavior: Assessing the mediating role of safety knowledge and motivation, Accident Analysis \& Prevention, 42(2), 2082-2093. https://doi.org/10.1016/j.aap.2010.06.021.

Yulita, Idris, M.A., and Dollard, M. (2016). Psychosocial safety climate: Past, present, and future research. In: A. Shimazu, R. Bin, M. Dollard, and J. Oakman (eds.), Psychosocial factors at work in the Asia Pacific (pp. 89-134). Cham, United States of America: Springer. 